\title{
Flipped Classroom, Flipped Teaching and Flipped Learning in the Foreign/Second Language Post-Secondary Classroom
}

\author{
Denise Mohan \\ University of Guelph \\ Canada
}

\section{Introduction}

Flipped classroom, flipped teaching and flipped learning are terms used to describe a pedagogy in which, in its earliest iteration, lectures were removed from their traditional in-class space and delivered via narrated PowerPoint recordings to be viewed by students prior to class meetings, thus freeing up in-class time for higher order cognitive tasks. These recorded slideshows later gave way to recorded video lectures as more instructors adopted the pedagogy. Students viewed the recordings when and where they chose, in their entirety or in chunks, once or multiple times, depending on their need. Pause and reflect activities, comprehension exercises, notetaking, quizzes and other types of engagement activities accompanied the recordings, depending on the instructor. The classroom became a space dedicated to a dynamic, student-centered process which allowed learners to clarify information and engage in application, analysis, synthesis and evaluation of the content of the video lecture. This was achieved through individual and group participation in cognitive activities aligned with the higher dimensions of The Taxonomy Table (Anderson and Krathwohl 28), with the instructor providing individualised assistance as needed. Thus, in a flipped teaching space, lecturing and traditional homework type activities switched their traditional places.

\section{Flipped Learning on the Student-Centered Learning Continuum}

American secondary school teachers Jonathan Bergmann and Aaron Sams, who began flipping their Chemistry classes in 2007, and who published their seminal work Flip your classroom: Reach every Student in Class Every Day in 2012, are generally credited with having created the term flipped classroom, though they themselves do not make such a claim (Bergmann and Sams, Flip your classroom 6). Their motivation was to allow for "more strategic use of in-class time for group work and individualized attention" (Bergmann et al. xii). When students interacted before class with content in screen captured PowerPoint lectures, more class time could be dedicated to application, analysis and practice of course content. However, their 2007 decision to flip did not represent a complete break from past pedagogical practice. In the early $90 \mathrm{~s}$, Harvard physics professor Eric Mazur, alarmed by test results showing that his students were failing at applying basic lecture content to solve problems, had already begun to provide his lecture notes to students prior to classes and implemented an in-class approach which he called "peer instruction" (10), a foreshadower of flipped learning. He assigned to students the responsibility of covering lecture content outside the classroom in advance of classes, which allowed time for inclass interaction between students as they applied theory to solve real-world problems, instructing each other in the process. Referencing Alison King's 1993 article calling for "guide on the side" pedagogy to replace "sage on the stage" tradition (30), Professor J. Wesley Baker, in a conference presentation in 2000, used the term "classroom flip" to describe a pedagogy he had implemented in his college classes. The rationale for this pedagogy and his description of its application are the same as the ones used several years later to describe the emerging flipped classroom model. In 2000, Lage, Platt and Treglia described the "inverted classroom," a model in which "events that have traditionally taken place inside the classroom now take place outside the classroom and vice versa. The use of learning technologies, particularly multimedia, provide new opportunities for students to learn" (32). In further descriptions by the authors, the inverted methodology meant "videotaped lectures were available for viewing in labs, or, if students brought in blank tapes, the university's audio-visual department made copies for home viewing" (Lage et al. 33). They also made available sound enhanced PowerPoint lectures which students could copy, print, download or purchase. The Khan Academy, created in 2006 and popularised world-wide after Kahn's 2011 TED talk, has as its foundation elements of the flipped model, not only with respect to instructors' and students' direct access to the Academy's online video content, but also in classrooms which partner with the Academy to achieve the learning objectives of their curricula (Khan, 2011). What all these pedagogical approaches have in common is the desire to afford each learner a rich, personalised, student-centered learning experience. This intention to situate students at the centre of the learning process goes back even further. A brief examination of some of the most recognised models of educational philosophy in just the last hundred years shows that the student-centered classroom has been championed by multiple educators and psychologists, with flipped learning one of its most recent iterations on the student-centered learning continuum. See figure 1. 
Figure 1. Flipped learning: another stop on the student centered learning continuum (Graphic created by author)

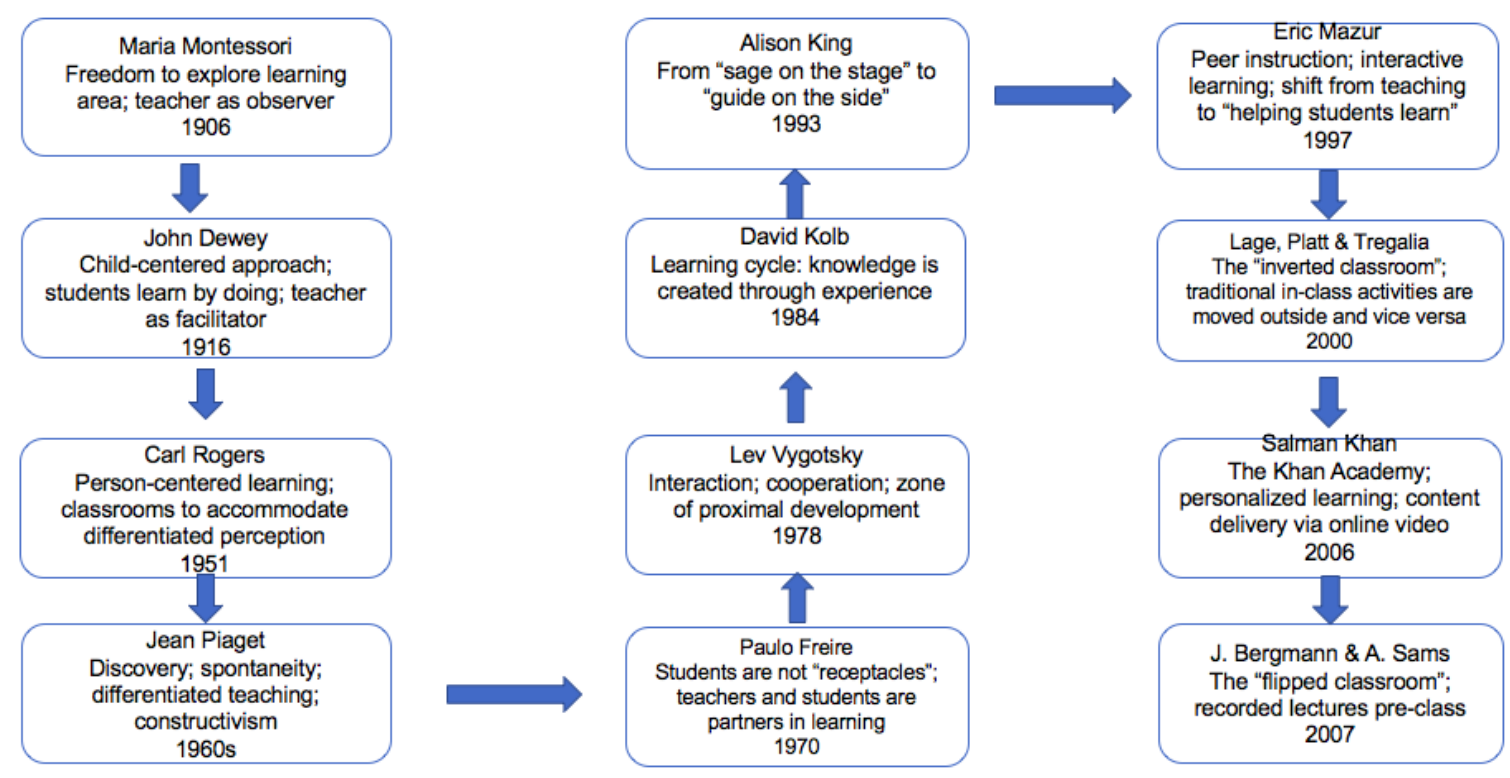

Since emerging in 2007, flipped learning has undergone modifications by multiple practitioners. Subsequent to Bergmann and Sams' use of narrated PowerPoint lectures, instructors began recording themselves lecturing, or sourced available online videos to replace in-class lectures. In 2007, "YouTube was just getting started, and the world of online video was in its infancy" (Bergmann and Sams, "Flip your classroom" 3) and it offered the exciting possibility of on-demand, web-hosted video. For many instructors, online video continues to be a defining feature of the flipped classroom (Millard 224; Muldrow 28; Talbert, "Inverted Classroom" 1). The impression that creating video content is a necessity in flipped learning is a detractor for many instructors considering adoption of flipped learning (Muldrow 28). However, the role of video or any other technology in flipped classrooms has evolved tremendously, with flipped learning experts affirming that video is not a necessity in flipped learning (Bergmann et al. 15; Honeycutt, Flipping the College Classroom 24; Morris et al. 3). The video is not the pedagogy; it is only a means of achieving the ultimate objective of the pedagogy. Technology of any type in flipped learning is now considered one possible tool that could lead to conditions for improved learning and student engagement, and should not drive the decision towards adoption of the flipped classroom. In recent publications, Honeycutt (Sept 2016) and Talbert (2017) describe flipped classrooms that are completely free of technology, and in its definition of flipped learning, the Flipped Learning Network makes no mention of video or technology of any kind:

Flipped Learning is a pedagogical approach in which direct instruction moves from the group learning space to the individual learning space, and the resulting group space is transformed into a dynamic, interactive learning environment where the educator guides students as they apply concepts and engage creatively in the subject matter. ("What is Flipped Learning?")

\section{Responses to the Flipped Classroom from Educators and Researchers}

Enthusiastic flipped learning practitioners and researchers attest to the successes and benefits of the flipped methodology, citing pre-class interaction with lecture content as a key contributor to achievement of their overarching objective: the best use of face-to-face time to provide a truly authentic, efficient, student centered, personalised learning experience. Their opinions, experiences and findings are documented in a growing body of academic publications, as well as on well-developed websites hosting online communities dedicated to the exploration, practice and development of flipped learning ${ }^{1}$, in informal commentary such as blogs, tweets and opinion pieces ${ }^{2}$, and in how-to videos ${ }^{3}$. Researchers and instructors from a variety of disciplines have published studies which showcase favourable results for the flipped approach. They report multiple positive outcomes, including: students performing better on exams (Harvey 123); students being more energised and engaged, less likely to turn to non-relevant activities, and taking ownership of their learning (Mok 10); students producing more cognitive comments, using more reasoning skills and displaying deeper information processing (Kim et al. 279); 
students showing "a deeper understanding of the subject concepts" (Nawi et al. 133); students being more alert and engaged (Auerbach 194), being better at application type activities (Harvey 120), displaying highly developed team-based skills and a higher level of discussion (Millard 224-225); instructors are able to give more individualised attention to students and build better relationships with them (Bergmann et al. 15; Gordon 339340).

Instructors and researchers also draw attention to the challenges of the flipped learning approach, citing a list of concerns, such as the demand on instructors' time to master software applications, prepare flipped video lectures and perfect them (Acedo; Enfield 25; Millard 228; Taylor 6); lack of institutional funding to acquire updated technology software and hardware, as well as lack of pedagogical training (Correa 123; "Flipped Classroom Trends" 5); lack of ongoing institutional support and a lack of recognition of the efforts of faculty who adopt new pedagogies as areas of practice and research (Duderstadt et al. 84-85; Honeycutt, "Flipping the College Classroom" 123); students not completing the pre-class video and associated activities (Correa 122; Honeycutt, "Flipping the College Classroom" 30); students not having the opportunity to ask questions at the time of viewing (Gordon 341; Taylor 6); and resistance from students who prefer traditional lectures (Kim; Talbert, "Inverted Classroom" 2; Taylor 8). Skeptics also refer to flipped learning's resemblance to long-standing pedagogical practices in which student-centered learning, "guide on the side" instructor facilitation and completion of loaded cognitive activities, coupled with the use of pre-class preparatory materials delivered via technology or not, is nothing new ("Flipped Classroom Trends" 7; Waldrop and Bowden 3).

\section{Flipped learning in Foreign/Second Language (FL/L2) Learning}

In FL/L2 classes, whether the principal focus is on mastery of grammar, writing, speaking, culture, literature, or any of the other fluencies articulated in the learning outcomes, conventional pedagogical practice has long required students to first interact with content that will be subsequently explored in the classroom. Preparatory work on a point of grammar might include a requirement to pre-read a section of the textbook, consult a PowerPoint presentation, watch an online video, perform cloze type exercises or complete a diagnostic quiz. Pre-class reading of a poem might involve seeking clarification of lexical items, note-taking, listening to a recitation of the poem or engaging in exercises which serve as proofs of comprehension and completion of the assignment. These activities correspond well with the first step of the flipped learning model - lower cognitive tasks are performed outside the classroom. Where FL/L2 classes merit further scrutiny is in the second step of the flipped learning approach - the follow-up activities that take place when students return to the classroom. If the instructor subscribes to a traditional teaching paradigm, face to face time might be dedicated to additional low stakes activities like repetition of vocabulary, decontextualised translation, explanation of basic rules of grammar, or reading aloud (not to strengthen oral or listening skills, but to cover content). These tasks all continue to represent rudimentary cognitive challenges in an instructor-centered classroom where students do not engage in activities in which "the focus shifts from form to meaning, from grammar to ... contextualised lexical focus". Neither does it facilitate "a task-based approach emphasizing language production and communication" (Chevalier, slide 50).

The body of critical evidence published on flipped learning is robust, including well documented case studies, examinations of learning outcomes, comparisons of performance as measured in final grades, statistical surveys and qualitative analyses. Such publications address flipped learning successes and challenges in a wide array of academic disciplines. However, FL/L2 is one of the areas for which critical research findings are just emerging in peer reviewed publications. A great deal of the available commentary focuses on instructors' experiences and is retrievable from blogs, interviews, op-eds and online community discussions. In a review of the available information on FL/L2 flipped classrooms, one observes that the focus is often on the tools used to convert content from in-class to out of class lectures. Discussions touch on the how-to of video software and voice recording tools, solutions to technology challenges and helpful products and websites. For instructors new to the approach, the technology is perhaps the biggest challenge in implementing the flipped model, and deserves all the attention it receives. However, of equal importance is knowledge of how to best capitalise on the time recovered in the classroom. For traditional instructors of FL/L2, this requires a paradigm shift in their pedagogy which is a prospect at least as challenging as mastery of new technology tools, and which merits discussion.

When FL/L2 instructors flip the focus from understanding and remembering decontextualised course content (grammar rules, conjugations, vocabulary lists) to using it in context through application, analysis, evaluation and manipulation of information, collaborative tasks, and creation of enhanced content or original artifacts, they essentially effect a flip of Bloom's Taxonomy (Marshall and DeCapua 86), as represented in figure 2 below. 


\section{Figure 2. Flipping Bloom's Taxonomy}

(Source: New Literacies Institute: http://nli2011.wikispaces.com/Bloom\%27s+taxonomy)
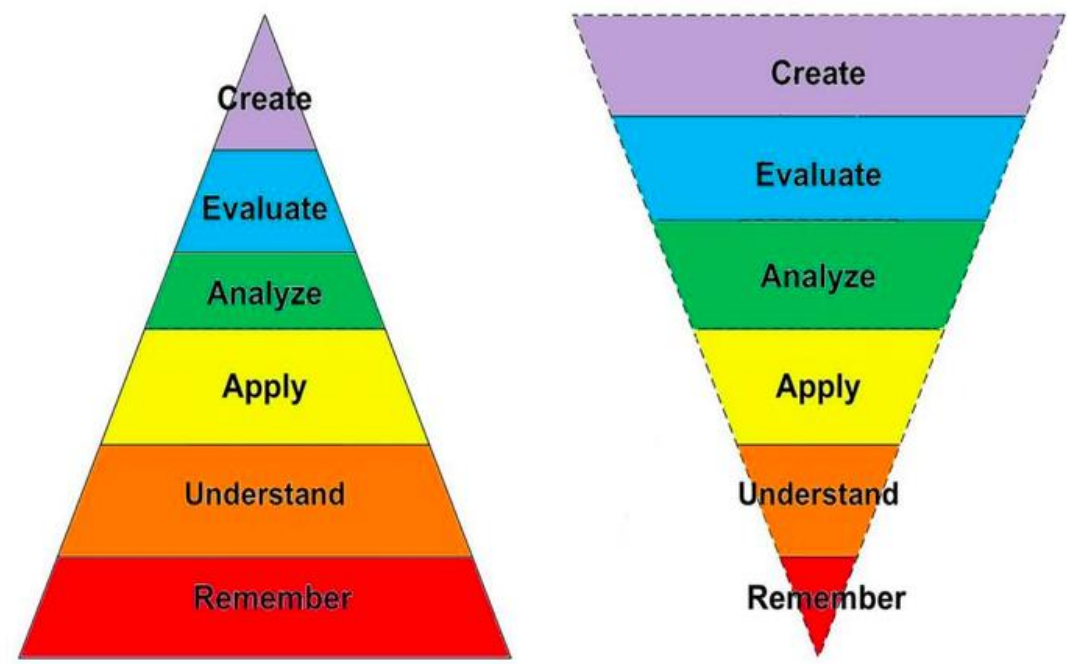

The original triangle on the left is divided into zones that demonstrate the placement of cognitive skills in ascending order of their impact on deep learning. Learning through remembering sits at the base, signifying it represents the least challenging cognitive skill, unlikely to produce "meaningful learning" (Anderson and Krathwohl 65). Despite its limited contribution to learning, its wide base is indicative of the quantity of attention this skill often receives in traditional FL/L2 classrooms. As the triangle is ascended, cognitive skills become more challenging, contribute more to meaningful learning and require more attention and practice, but the narrowing bands correspond to the decreased amount of time available to cultivate these skills in the traditional FL/L2 classroom. Creating, representative of the most challenging cognitive tasks, is rightfully placed at the apex of the triangle, but in terms of time dedicated to it, traditional pedagogy fails. In the flipped triangle on the right, remembering remains at the base to designate it the least important activity for fostering meaningful learning while its narrow band represents the amount of classroom time that should be dedicated to remembering type activities and assessments. The more challenging cognitive skills ascend the inverted triangle with progressively more time and attention given to them to create opportunities for the collaboration, problem solving, discovery and creation inherent in the learner-centered, flipped learning model.

How can FL/L2 instructors implement the principles of the flipped Taxonomy in their classrooms? As has already been acknowledged, the completion of lower order cognitive tasks outside the classroom has long been embedded in FL/L2 pedagogy. To fully implement the flipped model, activities inside the classroom must also represent a flip, moving away from further engagement in tasks limited to the lower zones of the Taxonomy. Group work, authentic communicative tasks, peer instruction, interpretation of information to create new meaning, research and inquiry, problem based learning, meta-reflection and instructional scaffolding are intrinsic elements of flipped pedagogy in student-centered learning spaces. The anecdotal narratives of FL/L2 instructors' about flipped learning tends to describe the benefits of learner-centered activities, but does not often provide details of specific in-class activities and their implementation. While it is beyond the scope of this article to collate a comprehensive list of possible activities to implement in flipped FL/L2 classes, it would be useful to profile some examples of in-class activities that could inspire instructors to re-imagine their use of flipped classroom time. The following are examples of such activities facilitated by the author in FL/L2 courses. In each case, low stakes learning has already occurred through pre-class interaction with course content, in-class time has already been dedicated to clarification of the content, as needed by the students, and the collaborative follow-up tasks below are elaborated in the presence of the instructor, who serves as facilitator, guide, sounding board, or when needed, as content expert providing assistance and feedback.

- After completing vocabulary and readings on a unit dedicated to social justice, students return to an intermediate level language class to engage in collaborative projects in which they use the readings and 
vocabulary to develop campaigns advocating for a social justice issue of their choosing. To create personalised context, they cast themselves as interns in an NGO competing for UN funds to help resolve their issue in ways they themselves conceive of, based on research they complete. Students are guided by a rubric detailing expectations and outcomes throughout the development of their presentation. They receive formative feedback, are given advice on error correction on their use of FL/L2, and have the option to practise their talk in front of peers, teaching assistants or the instructor. In the culminating activity, invited guests act as members of a "UN panel" which listens to the presentations, questions the presenters, provides feedback and makes judgements on which projects "receive funding."

- In an upper intermediate course with writing fluency as an identified learning outcome, students have the freedom to select the style of writing on which they wish to base their culminating writing activity. Throughout the semester, students and instructor discuss the characteristics of several genres of writing and progress individually and interactively through a series of writing workshops, producing short texts in each genre studied, on which they receive formative feedback from instructor and peers. At semester's end, each student is free to select a genre on which to build his or her summative writing assessment. Having studied the detective genre, for example, a student might choose to write a detective story. Another might select to write a newspaper article on a topic of their choice, applying the course content related to journalism.

- After learning about uses of the subjunctive mood in a chapter whose theme is the environment, students research their university's reduce, reuse and recycle programme and write letters to the university's president, commending university practices, recommending improvements and/or proposing additional initiatives. Alternatively, students create posters, plan a campaign, design a course module or organise an on-campus event related to the chapter's theme. In recognition of the fact that mastery of the subjunctive is a learning outcome in this language course, assessment criteria include proper application of the subjunctive. Making connections with the local community, students study their city's recycling programme and partner with immigrant support services to create bulletins which communicate the information to Spanish speaking newcomers.

- Based on preparatory readings in a unit about immigration, students of Spanish use class time to access national census figures to determine the percentage of residents at national and local levels who self identify as "of Hispanic origin". These figures serve as a springboard to in-class discussions examining students' experiences and interactions with Hispanic culture in their local community and further afield. This leads to many possible in-class activities, an example of which is the creation of a poster for an exhibit in which a student artistically expresses his or her experiences with Hispanic culture. For students whose linguistic ability is at an intermediate level and above, the follow-up activity is reimagined in several steps. Students are advised that in a future class, they will interview a Spanish speaking person who was born in a Hispanic country and now lives in their community. In a brain storming activity, students identify the topics that could be relevant in such interviews (immigration process, work and educational experiences, social integration, memories, comparisons, aspirations). Working in groups, students elaborate specific questions for their identified interviewee, based on his or her profile (retiree, graduate student, business owner, homemaker). After the interview is completed, group members rely on each others' skills to create a presentation, in a format of their choice, using their choice of information gleaned from the interview. Guests are invited back to the classroom to hear the presentations and answer follow-up questions from the entire class. The next step of this activity asks each student to critically assess his or her contributions to the project as well as those of each group partner. This step is completed using rubrics hosted on the online learning platform (OLP) and submitted directly to the instructor. Finally, students are asked to critically reflect on what they learned about the experiences of Hispanic immigrants in their community, how this information compares with views they had held prior to the interview, what they learned about their own country and community, and what most impacted them about the information provided by their guest. These reflections are submitted to the instructor via the OLP and students are invited to share their comments and impressions with their peers during a final in-class discussion. This project provides for multiple higher order cognitive tasks, including collaboration, self-assessment, accountability to group partners, peer instruction and peer assessment, meta reflection and fostering of critical thinking skills.

- After reading a novel, students can choose to engage in any of the following individual or group activities, always using the target language at a level compatible with the course: work collaboratively to write a play based on the novel and plan a performance; create an alternate conclusion to the novel; change one event in the novel and conceive of an alternate development of the plot; write a diary belonging to one of the characters. An 
instructor can also use the genre as inspiration for additional challenging and creative activities. For example, a crime novel examining guilt and innocence can serve as the foundation for a lively debate or a mock trial in the classroom.

- Instructors can expand the walls of the learning space to allow for learning outside of the physical classroom. Students can move around their campus in groups, with the objective of completing specific FL/L2 communicative tasks. Even if the world outside their classroom does not speak the language they are studying, they can complete tasks while communicating with each other in the target language, recording video of themselves to prove communication in the desired language during completion of the tasks. When they interact with community members who do not speak the target language, they might also record video of themselves retelling and discussing among themselves the acquired information in the target language. Instructors can easily set up parameters regarding task sharing, time limits and other requirements. Once back in the classroom, groups share information, make comparisons, note patterns and differences and draw conclusions, depending on the stated objectives of the activity.

- It must be noted that flipped learning is probably most difficult to implement in beginner level classes, given students' limited FL/L2 skills. At this level, a considerable amount of class time is dedicated to information exchange, discussion of language structures and attention to building a functional lexicon. Yet, by providing adequate prompts and framing of the activities, flipped pedagogy can be applied. As an example, after preparing vocabulary on home, furnishings and family using the text book and online images, recordings and games, beginner students, upon their return to class, are presented with a worksheet with the image of a house. They are free to make the house their own, by labeling the rooms as they wish, inserting furnishings of their choice and manipulating the image as they need to create additional living spaces. Students could be asked to tell who lives in the five bedrooms they selected for their home, or to ask about a peer's choice of appointments to their home using comprehensible communicative utterances, like "Who wants big garden?" or "No basement in your house?". This activity takes on an intercultural aspect when the instructor displays a Hispanic home which allows space for multi-generational living or displays decorative metal window bars, concepts not often reflected in Canadian home design. In the beginner level class, the greatest emphasis is placed on comprehensible output rather than linguistic accuracy.

- In a beginner class, an intercultural activity could be as simple as showing students photos representing both their "lived" culture and the culture being studied. In-class activities are performed individually and/or in groups and are targeted to improvement of multiple language skills and on intercultural observations. For example, students might write basic contrastive text about the foods, forms of dress, or public spaces represented in the images. Their text could be as basic as creation of lists to remark on colour contrasts, naming types of transportation, as well as identifying buildings and public spaces and the activities associated with each in both cultures. In group work, students could collaborate to create and orally present complete sentences to communicate their observations. The instructor, when providing scaffolded learning during this process, might need to provide students with additional language prompts not yet mastered, such as "I believe/ In my opinion/The difference is"/. A further iteration of this activity would see students make comparisons between the target culture and their own, based on their experiences in their country of origin and in the one(s) where the target language is spoken.

As can be seen in the activities described above, adoption of flipped teaching and learning can provide "a gateway for teachers to move to deeper strategies and transform their classrooms into dynamic, interactive learning environments where the educator's role is to guide students as they apply concepts and engage creatively in the subject matter." (Bergmann and Sams, "Flipped Learning Gateway" 23). The ideas described here are examples of activities that can be implemented in FL/L2 classes to create vibrant, challenging and creative learning opportunities for students. Such activities should, of course, be developed in alignment with the learning outcomes expressed in the course outline. For example, instructors in whose courses achievement of the learning objectives requires attention to syntax, semantics, lexical accuracy, phonology or stylistics will thoughtfully embed these objectives into the activities of their flipped classes.

\section{Considerations and Recommendations}

For any instructor thinking of flipping a FL/L2 class, there are several questions to consider, some of which follow. 
- What do I understand flipped learning to be and why do I want to adopt it in my FL/L2 class? If the answer revolves around a desire to stop lecturing in class and deliver content via assigned videos to facilitate additional exchange of information in the classroom, one is not adopting the flipped method. In the Flipped Classroom Trends Report, $79.3 \%$ of the respondents $(n=1,089)$ cite increased student engagement as their objective, and $75.8 \%$ say their aim is to improve student learning. First steps in answering this question involve research on the pedagogy and identifying ways to adopt and adapt it as needed to engage students, focus on interactive learning and improve learning in the context of their FL/L2 class.

- What do I wish my students had time to do in class, but they cannot do due to lack of time? The author's response is that I want students to speak the language, not speak about it; have ample opportunities to explore the histories, cultures and current events associated with the FL/L2 they are studying; have opportunities to build linguistic fluency in different contexts and apply the skills and knowledge they have acquired to complete personally meaningful communicative tasks; provide them activities which respond to their interests, and encourage their curiousity and independence; and give them choices in the ways they demonstrate their learning for assessment purposes.

- What resources do I have access to and which do I need to source to become knowledgeable about the flipped model? Consider whether you and the students have access to any technology required, seek advice on best practices from colleagues or teaching support staff and, seek out opportunities to attend training workshops and presentations.

- Which class(es) will I flip? While the types of activities associated with a flipped classroom can be easily implemented in a class of 25 students, will it be effective in a class of 50 or larger? In the Flipped Classroom Trends Report, almost $50 \%$ of respondents flipped or planned to flip classes of less than 25 students. A mere $20 \%$ would consider or had tried flipping in classes larger than this. For Correa, the flipped class should be small enough to allow the instructor to interact with each student at every class meeting (124).

- Must I flip my entire course? Flipping is not an all or nothing proposition. Many instructors flip small portions of their syllabus, or even one aspect of one topic in one class (Bergmann et al. 40; Correa 122). Mok reiterates this, advising, "It may also be preferable to convert part of a course instead of gunning for a "big-bang" revolution when rolling out a pilot" (10). Consider, too, whether some content might be best suited to an in-class lecture.

- What design principles must I observe in preparing the lecture content? Will I use technology to flip or not? If I choose to use video, is it essential that I make my own or is it acceptable to use video from other sources? Some practitioners suggest that assigning videos already available online is a valuable timesaver (Correa 123). Others do not recommend it, saying that videos featuring the instructor help to build a relationship between student and instructor (Bergmann et al. 15). FL/L2 videos featuring other speakers may discourage student engagement and mastery if the speakers have different accents from their teacher or speak too quickly (Yang 7). Consider also that the difficulty level and the scope of the discussions in pre-made videos might not align with the coverage of content in other course materials (textbooks, manuals, practice activities). The author recommends using videos commonly provided by textbook publishers, as they are well synchronised with textbook content. However, if an instructor selects other sources of videos, he or she should carefully preview them to be sure they are well aligned with other course content and activities.

- What happens when students do not complete the pre-class activities? Instructors at post-secondary level should stay true to the model; going to class and repeating the content will not encourage students to take ownership of the material, or of their own learning. It is worth the time to model in the classroom the behaviour that students are expected to embrace in their out of class activities (Benton qtd. in Muldrow 30; Bergmann et al. 47). To increase students' engagement in the pre-class learning phase, the preparatory materials should be accompanied by activities requiring interaction with the content. Pause and reflect moments, content based questions requiring simple responses, note-taking and creation of questions for in-class discussion are some strategies that may positively impact student completion of the preparatory materials. Where intrinsic motivation is lacking, some instructors assign points to pre-viewing and pre-class quizzing activities as a percentage of the student's final grade (Harvey 122). Enfield reiterates the usefulness of regular quizzing, saying, "The use of daily quizzes appeared to be a strong motivator for students to watch the videos" (17). 
- What kinds of assessments will I use in the flipped classroom? Student centered learning, by nature, is not preoccupied with grades (Miller), although assessments and grades are a reality in most university classrooms. Assessment can be situated anywhere on a spectrum from completely differentiated assessments which give each student the opportunity to prove mastery in a way he/she chooses when ready, to a single standardised assessment that everyone must complete simultaneously. Stiggins et al. provide useful principles of assessment, suggesting that classroom learning itself can be considered assessment, a sentiment which aligns well with flipped classroom pedagogy. They also list specific assessment targets that go beyond knowledge assessment and include assessing reasoning and skills, as well as "Product targets" (assessment of a product created by the student) and "Dispositional targets" ("characteristics that go beyond the academic... such as attitudes ... [and] feelings") (73-74). The University of Waterloo's Centre for Teaching Excellence provides assessment tips which align well with the flipped model of teaching: make assessments interesting, challenging and creative; assess the knowledge and behaviours you value most; when evaluating student work, establish a balance between evaluation of key content and error correction.

The examples above provide a brief introduction to the list of potential questions and issues to consider when contemplating adoption of flipped learning. Each instructor will decide which issues are relevant to his or her students, courses, learning outcomes and institution when building a solid rationale for implementation of flipped learning.

\section{Next Steps}

Given the high percentage of satisfied flipped instructors, and its ever-increasing adoption at primary, secondary and post-secondary levels, one can expect that the pedagogy will continue to be popular for some time to come. FL/L2 classes stand to benefit from this method, given that when well implemented, it maximises the amount of time available for students to communicate with each other and their instructor while completing authentic tasks in the target language. Some questions/issues which merit further attention, examination and action are:

- Many instructors will not flip, despite their interest, because they do not know how to do it. Professional development opportunities should be available for instructors who wish to flip. This is even more important in cases where entire institutions are moving in the direction of flipped learning.

- As has been noted, the flipped classroom of 2017 is not the flipped classroom of 1997. The pedagogy will continue to evolve, requiring support as information, language rules and linguistic patterns change, and newer technologies emerge. Continued institutional support and updating of class materials will be required.

- While evidence of the benefits and challenges of flipped learning in FL/L2 classrooms is available, a sizable percentage of it is based on personal observations and narratives. The available critical studies are limited to small groups of students in one-off courses (Enfield; Gordon; Guidry et al.; Yang). There is a need for continuing critical study on a larger scale, and publication of findings.

- Models of assessment in the flipped context merit further attention. While some instructors report increased student grades, others conclude that despite increased student engagement and participation, there are no appreciable gains in grades or proficiency. Guidry et al., who compared results between traditional and flipped Spanish classes, reported no statistical difference in students' grades or oral proficiency after one semester (11). In another study, significant improvement of knowledge occurred in only one of the two student groups participating in a flipped English language classroom study (Yang 13). In the Faculty Focus report "Flipped Classroom Trends," $74.9 \%$ of faculty reported increased student engagement, but only $54.6 \%$ reported evidence of improved student learning (10). Based on these results, further study on assessment is warranted.

\section{Conclusion}

In the approximately two decades since the term "flipped classroom" made its way into discussions on studentcentered learning and embedded itself in the consciousness of instructors, many have enthusiastically supported this approach, citing the multiple ways it which it facilitates active learning, leads to increased achievement (grades), and promotes "guide on the side" in-class facilitation by instructors. Referencing the results of the "Flipped Classroom Trends" report, $79 \%$ of respondents say they decided to flip to achieve increased student engagement, while $76 \%$ cited improved student learning as their goal. Further responses in the report show that overwhelmingly, the respondents confirm positive results relative to their goals in adopting the flipped model: 
$90 \%$ agree that students in flipped classrooms are more engaged; $77 \%$ agree that students' grades are improved; $77 \%$ say that students ask more questions; $83 \%$ report that students are more collaborative and $80 \%$ say students build more relationships with other learners. Still, not everyone is convinced about the usefulness and ease of application of the pedagogy. $27 \%$ of respondents consider it a fad; $20 \%$ would not adopt it because it is too time consuming and almost $40 \%$ say a lack of knowledge about the pedagogy prevents them from adopting it. Others take issue with flipped learning being called a "new" pedagogy, saying only the label is new, and the pedagogy has been in use in learner-centered, activity-based classrooms for a much longer time. Despite these reservations, flipped pedagogy will continue to be an important one as instructors respond to the demands for students to acquire the skills they need in the world beyond the classroom. In that world, information is available just the click of a mouse away in multiple formats, from a dizzying array of reliable as well as unreliable sources. As instructors, our role has changed from "transmitter of knowledge" and "sage on the stage" to that of "pedagogical architect" (Raschke 33) as we provide opportunities for students to critically assess the information they access, apply it to create new knowledge, work collaboratively, and build real-world skills. The flipped classroom goes a long way to meeting these objectives.

\section{Notes}

${ }^{1}$ Definitions of flipped learning are found in multiple online sources, including, as cited: "Definition of Flipped Learning"; "Flipped Learning Core Principles" and "About Flipped Classrooms."

${ }^{2}$ See, as cited, "The Flipped Learning Blog" and Julie Schell.

${ }^{3}$ A search for "Flipped Classroom" on YouTube renders "about 263,000 results": www.youtube.com/results?search_query=flipped+classroom 


\section{Works Cited}

"About Flipped Classrooms." Institute for Teaching and Learning, University of Queensland, http://www.uq.edu.au/teach/flipped-classroom/what-is-fc.html. Accessed 5 Jul. 2017.

Acedo, Mike. "10 Pros and Cons of a Flipped Classroom." Teachthought, www.teachthought.com/learning/blended-flipped-learning/10-pros-cons-flipped-classroom/. Accessed 5 Jul. 2017.

Anderson, Lorin W., and David Krathwohl. A Taxonomy for Learning, Teaching, and Assessing: A Revision of Bloom's Taxonomy of Educational Objectives. Longman, 2001.

Auerbach, Michael P. "Classroom Technology in the Twenty-First Century." Embracing New Paradigms in Education, compiled by H.W. Wilson, 2014, pp. 193-197.

Baker, J. Wesley. "The "Classroom Flip": Using Web Course Management Tools to Become the Guide by the Side." CCCU Annual Technology Conference, 23 June 2000, Azusa Pacific University, CA. PowerPoint presentation. www.classroomflip.com/files/baker 20000623 classroom flip CCCU.pdf. Accessed 23 Jun. 2017.

Bergmann, J. and A. Sams. Flip your classroom: Reach every Student in Class Every Day. International Society for Technology in Education, 2012.

--- "Flipped Learning Gateway to Student Engagement." Learning and Leading with Technology, vol. 41, no. 7, May 2014, pp. 18-23. www. iste.org/learn/publications/learning-leading. Accessed 4 Jul. 2017.

Bergmann, J. et al. Flipped Learning for English Instruction. International Society for Technology in Education, 2015.

Chevalier, Joan. "FLIPPING IT. Reversed Instruction in the Foreign Language Classroom." Department of Languages and Cultures, United States Naval Academy. PowerPoint Presentation. www.goo.gl/UN566T. Accessed 8 Jul. 2017.

Correa, Maite. "Flipping the Foreign Language Classroom and Critical Pedagogies: A (New) Old Trend." Higher Education for the Future, vol. 2, no.2, 2015, pp. 114-125. DOI:10.1177/2347631115584122. Accessed 24 Jun. 2017.

“Definition of Flipped Learning”. Flipped Learning Network, 12 Mar 2014, flippedlearning.org/definition-offlipped-learning/. Accessed 30 Jun. 2017.

Duderstadt et al. Higher Education in the Digital Age: Technology Issues and Strategies for American Colleges and Universities. Praeger, 2002.

Enfield, Jacob. "Looking at the Impact of Flipped Classroom Model of Instruction on Undergraduate Multimedia Students at CSUN." Techtrends, vol. 57, no. 6, Dec. 2013, pp.14-27.

“\#Flipblogs - An Extended Online Flipped Learning Conversation”. Flipped Learning Network. flippedlearning.org/flipblogs-extended-online-conversation/. Accessed 8 Jul. 2017.

"Flipped Classroom Trends: A Survey of College Faculty." Faculty Focus, Magna Publications, Aug. 2015, www.facultyfocus.com/free-reports/flipped-classroom-trends-a-survey-of-college-faculty/. Accessed 6 Jul. 2017.

“Flipped Learning Core Principles." Flipped Learning Global Initiative, flglobal.org/about-us/core-principles/. Accessed 8 Jul. 2017.

Gordon, Steven. "Experimenting with a Flipped Classroom." Evolving Entrepreneurial Education: Innovation in the Babson Classroom, edited by Victoria L. Crittenden et al., Emerald Group, 2015, pp. 335-348.

Guidry, Kevin R., et al. "The Connection Between Self-Regulated Learning and Student Success in a Hybrid Course." Association for Institutional Research Annual Forum, 31 May 2013, Long Beach, CA. Conference presentation. www.mistakengoal.com/docs/Self-regulated learning hybrid course.pdf. Accessed 6 Jul. 2017. 
Mohan, Denise. "Flipped Classroom, Flipped Teaching and Flipped Learning in the Foreign/Second Language

Post-Secondary Classroom." Nouvelle Revue Synergies Canada, N¹1 (2018)

Harvey, Sarah. "The "Flipped" Latin Classroom: A Case Study." Classical World, vol. 108, no. 1, Fall 2014, pp. 117-127. doi:10. 1353/clw. 2014. 0060. Accessed 4 Jul. 2017.

Honeycutt, Barbi. Flipping the College Classroom: Practical Advice from Faculty. Magna Publications, 2016.

---. "The Flipped Classroom Unplugged: Three Tech-Free Strategies for Engaging Students." Faculty Focus, 26 Sept. 2016, www.facultyfocus.com/articles/blended-flipped-learning/flipped-classroom-unpluggedthree-tech-free-strategies-engaging-students/. Accessed 14 Jul. 2017.

Khan, Salman. "Let's use video to reinvent education." TED, Mar. 2011, www.ted.com/talks/salman khan let s use video to reinvent education. Accessed 2 Jul. 2017.

Kim, Jeong-eun et al. "Exploring Flipped Classroom Effects on Second Learners' Cognitive Processing." Foreign Language Annals, vol. 50, no. 2, 2017, pp. 260-284.

Kim, Joshua. "6 Myths of the Flipped Classroom." Inside Higher Ed, 27 May 2014, www.insidehighered.com/blogs/technology-and-learning/6-myths-flipped-classroom. Accessed 24 Jul. 2017.

King, Alison. "From Stage on the Stage to Guide on the Side." College Teaching, vol. 41, no. 1, Winter 1993, pp. 30-35, www.jstor.org/stable/27558571. Accessed 5 Jun. 2017.

Lage, M. J., et al. "Inverting the classroom: A gateway to creating an inclusive learning environment." The Journal of Economic Education, vol. 31, no.1, Winter 2000, pp. 30-43, www.jstor.org/stable/1183338. Accessed 23 Jun. 2017.

"Learner-Centered Assessment." Centre for Teaching Excellence, University of Waterloo, www.goo.gl/2vtEin. Accessed 10 Jul. 2017.

Marshall, Helaine W., and Andrea DeCapua. Making the Transition to Classroom Success: Culturally Responsive Teaching for Struggling Language Learners. University of Michigan Press, 2013.

Mazur, Eric. Peer Instruction: A User's Manual. Prentice Hall, 1997.

Millard, Elizabeth. "5 Reasons Why Flipped Classrooms Work." Embracing New Paradigms in Education, compiled by H.W. Wilson, 2014, pp. 224-228.

Miller, Andrew. "Using Assessment to Create Student-Centered Learning." Edutopia. 2 Sept. 2015, www.edutopia.org/blog/assessment-create-student-centered-learning-andrew-miller. Accessed $12 \mathrm{Jul}$. 2017.

Mok, H. N. "Teaching Tip: The Flipped Classroom." Journal of Information Systems Education, vol. 25, no. 1, 2014, pp. 7-11. ink.library.smu.edu. sg/cgi/viewcontent.cgi?article=3363\&context=sis research. Accessed 7 Jul. 2017.

Morris, Cheryl, et al. "So you want to Flip Your Class...." Ion Lucidity, 28 Jul. 2012, www.morrisflipsenglish.com/blog-ion-lucidity/so-you-want-to-flip-your-class. Accessed 4 Jul. 2017.

Muldrow, Karen. "A New Approach to Language Instruction - Flipping the Classroom." The Language Educator, Nov. 2015, pp. 28-31, www.actfl.org/sites/default/files/pdfs/TLE pdf/TLE Nov13 Article.pdf. Accessed 6 Jul. 2017.

Nawi, N. et al. "To Flip or Not to Flip: The Challenges and Benefits of Using Flipped Classroom in Geography Lessons in Brunei Darussalam." Review of European Studies, vol. 7, no. 12, 2015, doi: 10.5539/res.v7n12p133. Accessed 8 Jul. 2017.

Raschke, Carl A. The Digital Revolution and the Coming of the Post Modern University. RoutledgeFalmer, 2003.

Schell, Julie. "Top 10 Hashtags for Flipped Classrooms and Flipped Teaching." Turn to Your Neighbour, 31 Oct. 2012, blog.peerinstruction. net/2012/10/31/top-10-hashtags-for-flipped-classrooms-and-flippedteaching/. Accessed 12 Jul. 2017. 
Mohan, Denise. "Flipped Classroom, Flipped Teaching and Flipped Learning in the Foreign/Second Language Post-Secondary Classroom." Nouvelle Revue Synergies Canada, №11 (2018)

Stiggins, Richard J., et al. Classroom Assessment for Student Learning - Using it Well. Assessment Training Institute, 2004.

Talbert, Robert. "Inverted Classroom." Colleagues, 2012, vol. 9, no. 1, article 7, www.scholarworks.gvsu.edu/colleagues/vol9/iss1/7. Accessed 15 Jul. 2017.

--- "No, you do not need to use video in flipped learning (and five alternatives)." 12 Jan. 2017, www.rtalbert.org/flipped-learning-without-videoembracing/. Accessed 5 Jul. 2017.

Taylor, Aaron. "Flipping Great or Flipping Useless? A Review of the Flipped Classroom Experiment at Coventry University London Campus." Journal of Pedagogic Development, vol. 5, no. 3, 2015, https://journals.beds.ac.uk/ojs/index.php/jpd/article/view/230/358. Accessed 15 Jul. 2017.

Waldrop, Julee B., and Melody A. Bowdon. Best Practices for Flipping the College Classroom. Routledge, 2016.

"What is Flipped Learning?" Flipped Learning Network, 12 Mar. 2014, flippedlearning.org/definition-of-flippedlearning/. Accessed 2 Jul. 2017.

Yang, C.C.R. "An Investigation of the Use of the 'Flipped Classroom' Pedagogy in Secondary English language Classrooms." Journal of Information Technology Education, vol.16, 2017, pp. 1-20, www.informingscience.org/Publications/3635. Accessed 2 Jul. 2017. 